UNDERGRADUATE RESEARCH IN NATURAL AND CLINICAL SCIENCE AND TECHNOLOGY (URNCST) JOURNAL Read more URNCST Journal articles and submit your own today at: https://www.urncst.com

\title{
Scinapse 2019-2020 Undergraduate Science Case Competition: Augmented Biology
}

Clarissa Ngo, BSc Student [1]*, Linda Mardiros, BSc [2], Rashida Rajgara, MSc [2]

[1] Faculty of Science, University of Ottawa, Ottawa, ON, Canada

[2] Faculty of Medicine, University of Ottawa, Ottawa, ON, Canada

*Corresponding Author: cngo016@uottawa.ca

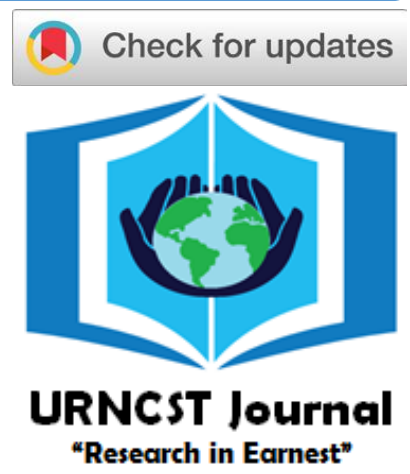

Note: Correction added after original version published on March 10, 2020. We regret any inconvenience caused.

\begin{abstract}
The Scinapse Undergraduate Science Case Competition (USCC) provides an opportunity for undergraduate students to experience the development of a novel research proposal. A case is presented to all participants and, using in-depth literature search (publications, reports, studies and published writings), students connect and pinpoint key elements allowing them to develop a hypothesis in support of the case in question. Participants also develop a methodology which will test the validity of their hypothesis. This year's case topic was inspired by recent scientific advances in the field of biological augmentation. This topic provided an opportunity for participants to create research proposals exploring potential applications of gene editing, biomedical engineering, virtual reality, and more. In teams of 2-4, undergraduate students tackled the case and provided novel research ideas that may hold the key to addressing current global issues, such as those relating to health care, climate change, and food security. In total, the 2019-2020 USCC attracted 731 undergraduate students from 11 universities across Canada and the United States. The top $10 \%$ of written submissions are highlighted in this abstract booklet.
\end{abstract}

Keywords: augmented biology; virtual reality; artificial intelligence; undergraduate research; science case competition.

Table of Contents

Scinapse Abstracts

pg. A01-A11

\section{Conference Abstracts}

Note: These abstracts have been reproduced directly from the material supplied by the authors, without editorial alteration by the staff of the URNCST Journal. Insufficiencies of preparation, grammar, spelling, style, syntax, and usage are the authors.

\section{$\underline{\text { Scinapse Abstracts }}$}

Of mice and fish: Effects of fluorinated zeolite particles incorporation in decellularized tilapia skin scaffold on oxygenation

Ryan Jack Revilla [1], Erin Joy Heifetz [1], Jessica Wang [1], Zoe Ang [1]

[1] McMaster University, Hamilton, Ontario, Canada L8S 4L8

Decellularization and recellularization are revolutionary developing processes in science that have great potential in increasing compatibility and availability of organ and tissue donation, due to the ability of utilizing individual stem cells. However, a major complication with use of decellularized scaffold material is insufficient oxygen delivery and subsequent necrosis before the establishment of new vasculature. This experiment proposes a novel oxygenation method to improve upon current decellularization scaffolding technologies, as applied to skin grafting. This method will attempt to increase oxygenation via incorporation of $0.25 \mathrm{wt} . \%, 0.5 \%, 1 \%$, and $5 \%$ of fluorinated zeolite particles in a decellularized tilapia skin scaffold, which will be prepared by applying two chemical detergents. The scaffold will then have all cellular material removed, and after sterilization will be recellularized using rodent stem cells. The prepared graft, along with the control methods of a commercial synthetic acellular skin scaffold and one prepared with no zeolite particles will be used as skin 
UNDERGRADUATE RESEARCH IN NATURAL AND CLINICAL SCIENCE AND TECHNOLOGY (URNCST) JOURNAL Read more URNCST Journal articles and submit your own today at: https://www.urncst.com

grafts on rodent models. Necrosis will be used to indicate success of oxygenation and cell survivability. It will be measured through qualitative morphological characteristics and microscopic observation.

\author{
Potential application of AgNPs encapsulated in BAPCs to circumvent antibiotic resistance in methicillin-resistant \\ S. aureus \\ Russell Leong [1], Joan Lee [1], Chelsea Zhang [1], Frank Chen [1] \\ [1] McMaster University, Hamilton, Ontario, Canada L8S 4L8
}

Antibiotic resistance has been labelled as one of the most concerning public health issues worldwide due to many species of bacteria such as methicillin-resistant Staphylococcus aureus (MRSA) becoming resistant to common antibiotics. This proposal aims to overcome the antibiotic-resistant ability of MRSA by targeting its essential iron receptors with antibiotic silver nanoparticles (AgNPs) encapsulated in branched amphiphilic peptide capsules (BAPCs). AgNPs have proven to be effective as an antibiotic with a low potential for antibiotic resistance due to its multifaceted intracellular attack mechanism. BAPCs, which are stable and biocompatible with the human body, are used to store AgNPs to confine its toxicity. The iron receptors of MRSA are targeted by attaching functional ligands replicated from endogenous heme and siderophore mediators to the surface of BAPCs. By targeting siderophore and heme uptake receptors, the likelihood of developing antibiotic resistance is lowered because iron uptake vital to the bacteria would be attenuated should mutations that alter iron receptors occur. This novel therapy can be considered as a preliminary step in overcoming antibiotic resistance and has the potential to act as a versatile antibiotic for other bacterial strains with appropriate modifications to BAPCs.

Using tissue-specific, biodegradable cross-linked hydrogels for the delivery of mesenchymal stem cells in model mice for potential treatment of osteoporosis in postmenopausal women

Marvin Yan [1], Sufal Deb [1], Carmina Isidoro [1]

[1] McMaster University, Hamilton, Ontario, Canada L8S 4L8

As the scientific community continues to make significant breakthroughs, augmented biology has become a primary area of interest in enhancing natural biological features. Given such discoveries, potential clinical applications have arisen to aid in the enhancement of at-risk populations. Primarily affecting women over the age of 50, postmenopausal osteoporosis is one condition that may benefit from an augmented approach. Associated with bone loss and fragility, postmenopausal osteoporosis may induce greater risks of fractures and other related injuries in the ageing female population. Using ovariectomized mice models, a potential treatment for this bone loss is the enhancement of bone reformation via mesenchymal stem cell (MSC) delivery in a cross-linking synthetic hydrogel injection. In place of the currently invasive gold standard of care, this therapeutic has great clinical potential. By studying the ovariectomized mice models and measuring bone densities using dual-energy x-ray absorptiometry, this proposal plans to investigate the potential effectiveness of crosslinked hydrogeldelivered MSCs in treating postmenopausal osteoporosis.

Inhibition of splicing factors using siRNA to delay the onset of aging Abdullah Khan [1], Hassan Sheikh [1], Huzaifa Mudassir [1], Mohammed Salah [1] [1] McMaster University, Hamilton, Ontario, Canada L8S 4L8

The use of RNA therapeutics, specifically siRNA, paired with a nanoparticle delivery system can be utilized to inhibit hnRNP expression. This decreases the severity of phenotypes that are characteristic of senescent cells and increases the lifespan of organisms. siRNA regulates the expression of genes through a process known as RNA interference. In this case, the siRNA silences the hnRNP gene by targeting complementary hnRNP mRNA for degradation. hnRNP is shown to be an inhibitor of splicing factors which are crucial to the regulation of genes. Under expression of these splicing factors leads to many diseases including Alzheimer's, spinal muscle atrophy, multiple sclerosis, and various types of cancers. In this review, Pachyuromys duprasi will be used as a mouse model to determine the effects of siRNA on senescence. Two experimental groups will be used to determine the effectiveness of the experiment. They are divided based on the timing of dosage and results will be compared to corresponding controls. 
UNDERGRADUATE RESEARCH IN NATURAL AND CLINICAL SCIENCE AND TECHNOLOGY (URNCST) JOURNAL Read more URNCST Journal articles and submit your own today at: https://www.urncst.com

\section{CRISPR/Cas9-HDR gene therapy to treat OCA1 albinism}

Sofia Ivanisevic [1], Sarah Yang [1], Colleen Dawson [1], Ashlee Gonsalves [1]

[1] McMaster University, Hamilton, Ontario, Canada L8S 4L8

Gene therapy has gained large interest in the scientific field for potential therapeutic applications since the development of CRISPR/Cas9 genome editing techniques. The effectiveness of CRISPR/Cas9 to treat disease has been demonstrated in studies regarding HIV, liver disease, and triple negative breast cancer, but little is known about its ability to treat oculocutaneous (OCA1) albinism. OCA1 albinism is associated with mutation in the tyrosinase enzyme gene (TYR), and is characterized by little to no melanin synthesis, particularly in hair follicles, skin, and eye tissues. We propose the use of hydrodynamic tail vein injections of wildtype TYR ssDNA with guide RNA and cas9, as per CRISPR/Cas9-HDR gene therapy techniques, to increase melanin synthesis in B6 albino mice. Melanin quantities will be assessed after mouse sacrifice at 4 months of age by collecting skin, eye tissue, and hair follicles and then quantifying melanin using spectrophotometric techniques. Melanin quantities will then be compared to a negative control cohort. If this gene therapy is successful in increasing melanin synthesis, CRISPR/Cas9-HDR could prove a promising field in OCA1 albinism treatment.

Blue genes to blue jeans: A proposal for the synthetic production of indigo in genetically engineered Gossypium hirsutum ovule cultures Amy Liu [1], Dani Lee [1], Cynthia Gu [1], Yuxin Bai [1]

[1] McMaster University, Hamilton, Ontario, Canada L8S $4 L 8$

The environmental ramifications of dyeing cotton indigo to produce blue denim has warped the beloved garments from a global fashion staple into a primary source of global pollution. To make the production of indigo cotton more sustainable, the indigo-dyeing process can be entirely eliminated by genetically modifying the cotton plant to directly produce indigo fibres. We propose integrating previous research to execute a proof-of-concept that will express indigo dye in isolated cotton fibres. Our approach first creates a plasmid with the necessary genes to produce indigo in cotton and then designs the timing of indigo expression to match fibre development. The successful realization of our proposal and vision will not only dramatically reduce the environmental consequences of staying chic and in style, but also further synthetic plant biology research.

\section{Augmenting the breast implant: A proposal for modified cell-based nanocellulose silicone implants Hardil Bhatt [1], Alyshia Laidlaw [1], Leander Ovid [1], Aarsh Shah [1] [1] McMaster University, Hamilton, Ontario, Canada LSS $4 L 8$}

Breast augmentation is a commonly performed cosmetic procedure which increases the size of a woman's breast using synthetic implants. Currently, most implant materials are silicone-based, as they mimic the feel of a natural breast. However, the use of a foreign material in the body often leads to a condition known as capsular contracture. This complication involves the formation of hard and dense capsular tissue. It is often observed surrounding breast implants following surgery. Capsular contracture arises from a negative immune response to foreign material. As research suggests mammalian cells can grow and proliferate on nanocellulose scaffolds, we hypothesize this method can be used to create a modified silicone implant. We propose the new implant will be coated with a bacterial nanocellulose membrane adhered to adipose stem cells of the recipient. We predict that by having recipient cells on the surface of the implants, the likelihood of a negative immune response could be reduced, thus lowering the incidence of capsular contracture. To test this hypothesis, we propose a murine study using the modified implants. Mice will either be given normal silicone implants or the modified nanocellulose-ASCs coated implants, and observed post-operatively using in vivo micro computed tomography and histological analysis of capsular tissue. The results of this experiment should demonstrate a reduction in the proliferation of capsular contracture in the experimental mice, when compared to the control mice. It is hoped that if results are positive, this study can open up the possibility of using modified silicone implants in human breast augmentation. 
UNDERGRADUATE RESEARCH IN NATURAL AND CLINICAL SCIENCE AND TECHNOLOGY (URNCST) JOURNAL Read more URNCST Journal articles and submit your own today at: https://www.urncst.com

Combating antibiotic resistance using CRISPR genetic modification in Lactobacillus and conjugation with $C$. jejuni to result in bacterial necrosis

Julia Habashy [1], Marina Boutros [1], Maria Azab [1], Christina Hanna [1]

[1] McMaster University, Hamilton, Ontario, Canada L8S 4L8

Microbes' ability to evolve, along with the overuse of antibiotics, has given rise to a crisis of antibiotic resistance, particularly among Gram-negative bacteria. This application proposes to investigate an alternative method to target gramnegative bacteria and effectively destroy them for the healing of infections. The proposed mechanism is based on several experiments using the popular genetic engineering tool of CRISPR. The common experiments use bacterial conjugation as a delivery mechanism for CRISPR modified material to destroy the recipient bacteria. We propose to use in vitro experiments to genetically modify a common bacteria in the gut, Lactobacillus. We will insert a unique sequence found in the harmful $C$. jejuni bacterial genome as a spacer sequence on the CRISPR system of Lactobacillus. With conjugative transfer between the two strains of bacteria, the spacer sequence will be transferred to $C$. jejuni and the CRISPR system will cleave the $C$. jejuni sequence, causing the bacterial cell to lose its function. This will determine the possibility of genetic engineering as a solution to the antibiotic resistance crisis.

PrPsc antibody delivery system across the blood-brain barrier via receptor-mediated transcytosis of gold nanoparticle-transferrin complexes Sara Mansouri [1], Lilian Raphael [1]

[1] Western University, London, Ontario, Canada N6A 3K7

Prion related diseases, such as Creutzfeldt-Jakob disease (CJD), are known to be fatal and contagious, yet no effective treatment has been found. Prions are naturally found within the brain, separated from blood circulation by the highly selective blood-brain barrier (BBB). Misfolded prions - such as PrPsc, the scrapie isoform of PrPc prions - are difficult to target due to this barrier, thus our proposal investigates the use of receptor-mediated transcytosis to allow nanoparticle-antibody complexes to traverse the BBB and target PrPsc prions found on cell surfaces and in synapses. This investigation uses gold nanoparticles linked to a complex consisting of the monoclonal antibody 6D11 and transferrin via an acid-cleavable linker. The complex binds to transferrin receptors found on the surface of endothelial cells and enters the cell through endocytosis. The linkers are then cleaved, and the gold nanoparticle and antibodies are released into the interstitial fluid of the brain. The 6D11 antibody can then tag PrPsc for lysosomal degradation. Different doses of this treatment are tested in vitro and in vivo in mice, and then in vitro in human endothelial cells, and the presence of the prions is monitored for effectiveness of the treatment. It is hypothesized that this treatment will have an effect on the presence of PrPsc in the brain, and it is specifically predicted that the treatment will reduce the number of PrPsc found in the brain. This investigation applies to potential treatments in a variety of prion related diseases, neurodegenerative diseases, gene therapy, and medical imaging.

Investigating the neuroprotective and immune effects of gut microbiota metabolites following stroke Jeng-liang Wu [1], Justin Yang [1], Sarah Buck [1]

[1] Western University, London, Ontario, Canada N6A 3K7

Metabolic byproducts of human gastrointestinal microbiota are suggested to influence neuroinflammation and immune response in the brain via the brain-gut axis, but current research has not clearly identified these interactions, particularly with in vivo models. The proposed study investigates the neuroprotective effects of short-chain fatty acids produced by gut microbiota. Specifically, this project aims to identify how increased butyrate and propionate production by Roseburia inulinivorans,

a species of intestinal bacteria, affects post-stroke complications in mouse models. cDNA of phosphate butyryltransferase and CoA-dependent propionaldehyde dehydrogenase enzymes will be ligated into plasmid vectors and transformed into competent Roseburia inulinivorans to increase the production of butyrate and propionate respectively. Modified bacteria will be transplanted into a mouse model where stroke will be induced by endothelin-1 injection to the right insular cortex. Genetic analysis of stool samples and various immunohistological staining techniques will quantify relative microbiota populations, neuroinflammation, and immune cell infiltration at stroke site. If reduced inflammation and greater immune cell recruitment are observed as expected, it can be concluded that the metabolites produced by gut microbiota exert neuroprotective effects and are involved in anti-inflammatory mechanisms and immune responses at the site of stroke. These findings could potentially identify novel therapeutic targets for stroke treatment, and future studies could pinpoint the pathways through which the metabolites exert their effect.

Ngo et al. | URNCST Journal (2020): Volume 4, Issue 3

DOI Link: https://doi.org/10.26685/urnest.184 
UNDERGRADUATE RESEARCH IN NATURAL AND CLINICAL SCIENCE AND TECHNOLOGY (URNCST) JOURNAL

Read more URNCST Journal articles and submit your own today at: https://www.urncst.com

Use of agrobacterium-mediated transformation of Vitis vinifera with attB to confer resistance against Pierce's disease Shan Grewal [1], Manvir Duhra [1], Simarjot Sohal [1]

[1] Western University, London, Ontario, Canada N6A $3 K 7$

Pierce's Disease is the infection of grapevine (Vitis vinifera) by the bacterium Xylella fastidiosa, causing xylem tissue to clog, and water transport to be impeded. Infected $V$. vinifera eventually die of dehydration. The proposed study examines the use of Agrobacterium-mediated transformation of $V$. vinifera to produce strains resistant to $X$. fastidiosa infection. The transgenic plants are engineered to carry the gene attB, isolated from the Drosophila genome. The encoded antimicrobial protein, attacin, is able to kill gram-negative bacteria such as $X$. fastidiosa. Successful transformation and resistance would offer a new means of bacterial resistance to the grape and wine industry, without the need for antibiotics or bactericides.

Targeting alpha-1-antitrypsin deficiency: Beyond CRISPR-Cas9-mediated gene correction Rebecca Lau [1], Jasmine Wen [1]

[1] Western University, London, Ontario, Canada N6A $3 K 7$

Liver disease continues to pose a major complication for children and adults affected by alpha-1-antitrypsin (AAT) deficiency. Mutation of AAT ( $\mathrm{Z}$ mutant E342K) leads to protein aggregation in the endoplasmic reticulum of the liver, preventing its secretion into the bloodstream and ultimately into the lungs. Previous attempts with CRISPR-Cas9 technology to restore wildtype (WT) AAT levels in the circulation showed only a modest increase. Here, a novel, multi-faceted approach is presented, which offers an attractive therapeutic method to combat challenges of alpha-1-antitrypsin deficiency. CRISPRi, with an enhanced transcriptional repressor (dcas9-KRAN-meCP2m), silences expression of mutant alpha-1-antitrypsin, while CRISPR induced homology-directed repair inserts a fully functioning WT alpha-1-antitrypsin under the transcriptional regulation of a similarly expressed protein, AAC. Furthermore, lipid nanoparticles provide highly-specific liver-targeted delivery. Subsequent analyses using cell-based studies and transgenic mice models would be performed to validate the efficacy of the treatment. The importance of extending CRISPR beyond its well-known genome editing function is highlighted, as well as enhancing tissue-specific targeting. Within the evolving world of genome-editing technologies, new therapeutic approaches must be explored in hopes of alleviating alpha-1-antitrypsin deficiency mediated health problems.

\author{
The development of a caffeine analogue to stimulate cerebral spinal fluid production and to increase glymphatic \\ efficiency \\ Matthew Shammas-Toma [1], Mila Huhtala [1], Kelsey Lee [1], Disha Rawal [1] \\ [1] Western University, London, Ontario, Canada N6A $3 K 7$
}

The present study aims to investigate the effects of a caffeine analogue on cerebrospinal fluid (CSF) production. The glymphatic system involves the use of CSF for clearance of waste such as beta-amyloid protein (AB) from the brain. Previous research implicates the impairment of this process in Alzheimer's Disease (AD). Furthermore, CSF production declines in healthy aging and has been a potential cause to decreased glymphatic function. Caffeine consumption is linked to increased CSF production, along with a lower risk for $\mathrm{AD}$. The present study looks to combat the adverse effects of caffeine through the development of a caffeine analogue which targets A1 and A2A receptors to stimulate CSF production, while having reduced affinity for receptors implicated in caffeine's negative effects such as Cardiac Ryanodine Receptors (RyR2).

Novel approach using recombinant-DNA infused $E$. coli bacteria in Acheta domesticus to provide a more sustainable method for cricket-derived protein

Hertek Gill [1], Aditya Prashar [1], Yudhvir Bhatti [1], Ammar Alam [1]

[1] University of Ottawa, Ottawa, Ontario, Canada K1N 6N5

With the global human population increasing at an exponential rate, global meat consumption has also increased to meet rising protein demands. This is currently resulting in an unsustainable level of animal-derived protein production. However, a new ecologically friendly replacement source of protein is currently being developed and improved. Insects, particularly crickets, are known to have a high protein concentration and could thus offer a sustainable alternative to animal-based protein. Despite this, there is still a long way to go before crickets can replace meat altogether. One factor being that due to their small size they provide very small amounts of protein. However, if their protein concentration by mass could be 
UNDERGRADUATE RESEARCH IN NATURAL AND CLINICAL SCIENCE AND TECHNOLOGY (URNCST) JOURNAL Read more URNCST Journal articles and submit your own today at: https://www.urncst.com

increased, they would possibly become a viable alternative. One way to increase the protein content in crickets would be to boost the production of Insulin-like Growth Factor-1 (IGF-1). Using a type-II restriction endonuclease enzyme, the IGF-1 gene would be extracted from crickets and added to a plasmid, which would then be inserted into $E$. coli bacteria. These bacteria would be provided to the crickets through their feed. If this bacterium allowed for the creation of more IGF-1 it would be expected that mice fed a diet of genetically modified crickets would have a higher protein yield.

\title{
Oral immunization with plant-derived M72/AS01 BCG antigen: Towards the development of an edible recombinant maize-based vaccine against tuberculosis \\ Saif Dababneh [1], Olivia Facchin [1] \\ [1] University of Ottawa, Ottawa, Ontario, Canada K1N 6N5
}

Mycobacterium tuberculosis infections constitute a crisis for the global pediatric community. To date, the only approved vaccine for tuberculosis prevention is a live-attenuated substrain of Mycobacterium bovis known commercially as bacille Calmette-Guerín (BCG). Though limited in its efficacy, BCG harbours considerable potential as a candidate for childhood immunization against miliary tuberculosis and tuberculous meningitis, both of which bear high mortality and morbidity rates. However, despite the promise it possesses, we are currently witnessing a global shortage of BCG, with South African provinces exhibiting the most significant decrease in supply. To alleviate this shortage, we endeavour to develop a sustainable, recombinant technology in planta by employing maize as a bioreactor for BCG antigen M72/AS01 expression using

Agrobacterium-mediated gene transfer. Transformed maize will be regenerated and harvested for use as oral vaccines and validated for immune conference in guinea pigs. If effective, the recombinant maize warrants potential for utilization in human populations as a reproducible and edible source of the BCG vaccine that exploits existing agriculture to mitigate shortages and ultimately develop a platform for other plant-derived vaccines.

\author{
Gene editing Ralstonia eutropha to combat climate change and increase fuel efficiency in modern transportation \\ vehicles \\ James Han [1], Ashna Zaman [1], Myriam Hamza [1], Ayesha Siddiqua [1] \\ [1] University of Ottawa, Ottawa, Ontario, Canada K1N 6N5
}

Ralstonia eutropha $\mathrm{H} 16$ (R. eutropha) is a soil bacterium that is able to grow by primarily depending on hydrogen gas $\left(\mathrm{H}_{2}\right)$ or carbon dioxide $\left(\mathrm{CO}_{2}\right)$. Strains of $R$. eutropha have been genetically engineered for electromicrobial conversion of $\mathrm{CO}_{2}$ to $\mathrm{C}_{4}$ and $\mathrm{C}_{5}$ alcohols in prior research. Therefore, the template of this proposal will be to use this genetically engineered $R$. eutropha bacteria to create a filtration system for cars with a goal of lowering $\mathrm{CO}_{2}$ emissions of automobiles to combat climate change. $R$. eutropha uses the enzyme $\beta$-carbonic anhydrase $(\beta$-CA) to sustain itself through the process of interconversion of $\mathrm{CO}_{2}$ and bicarbonate, and the gene responsible for the expression of $\beta$-CA is referred to as can. It has been observed that the growth of $R$. eutropha depends on $\beta$-CA, particularly when there are low concentrations of $\mathrm{CO}_{2}$ present, such as at atmospheric levels. The aim of this proposal is to use the CRISPR-Cas9 system alongside electroporation techniques to implement more of the can gene into the genome of R. eutropha to produce more of the enzyme $\beta$-CA, causing an increased survival rate of $R$. eutropha in low $\mathrm{CO}_{2}$ concentrations. This increased survival rate of $R$. eutropha in less favourable $\mathrm{CO}_{2}$ conditions will allow for a filtration product to be implemented into the tailpipes of automobiles, which will lower $\mathrm{CO}_{2}$ emission rates.

A novel nutrient-boosted bone filler to accelerate the healing process of femoral neck fractures in elderly patients Geneviève Haché [1], Lucie Péléja [1], Andrea Szafran [1], Alexie Leclerc [1]

[1] University of Ottawa, Ottawa, Ontario, Canada K1N 6N5

Hip fractures are a common type of fracture, and their prevalence increases in elderly patients, especially in the case of femoral neck fractures. There are many methods available to treat femoral neck fractures, however, the healing time can be relatively long and challenging, especially for the elderly population. Our proposal focuses on the creation of a novel and innovating healing technique as a way to accelerate the healing of femoral neck fractures in elderly patients. The goal is to mobilise patients within a shorter time span, in order to minimize the negative impacts of the long healing processes and its wellness consequences. Accelerating the healing process can lower the frequency of morbidity, mortality, chronic pain, acquisition of other chronic conditions, and would offer a higher quality of life to those patients. Using well-established 
UNDERGRADUATE RESEARCH IN NATURAL AND CLINICAL SCIENCE AND TECHNOLOGY (URNCST) JOURNAL Read more URNCST Journal articles and submit your own today at: https://www.urncst.com

compounds used in synthetic bone grafts, we propose to create a bone filling paste that has the ability to enhance and facilitate the healing process for patients with femoral neck fractures. Experimental trials using the synthetic paste will be conducted on rat subjects, using a randomized control trial. We will collect data on sealing properties, inflammatory reactions and evaluate the risks on the health of the subjects. Various Volumes of $1 \mu \mathrm{L}, 5 \mu \mathrm{L}$, and $10 \mu \mathrm{L}$ at concentrations of $1 \%, 5 \%$ and $10 \%$ will first be tested to determine the rate of healing in rat models. For each concentration of the paste, healing time between the treatment group and the control group will be evaluated.

\section{Adapting CRISPR-Cas9 prime editing to mitochondrial DNA editing Jonathan Buiel [1], Adrien Prince-Hallée [1], Daniel Pelletier [1] [1] University of Ottawa, Ottawa, Ontario, Canada K1N 6N5}

Prime editing (PET) is a recently published variant to traditional CRISPR-Cas9 gene editing allowing for much greater specificity, efficiency, and control on DNA mutations inserted into target sequences. As such, the tool is more appealing for potential gene therapy. Currently, PET only allows for gene editing within the nucleus, but gene therapy could also be highly beneficial to mitochondrial DNA (mtDNA) in cases of mitochondrial genetic disorders that occur when a pathogenic mutation is found in mtDNA. To that end, we hope to develop an effective and specific variant of PET which would target mtDNA. We propose achieving this goal by (a) Adding a mitochondria-targeting sequence to the modified Cas9 enzyme used in PET. (b) Using a set of complementary guide RNAs that target mtDNA. (c) Testing efficiency and specificity of these new biochemical tools with varying parameters such as GC ratio of target genes, guide RNA length and type of the desired mutation on harvested mitochondria. (d) Applying the developed tool to in-cell mitochondria and focusing on known troublesome genetic mutations in mtDNA.

\section{Using genetically engineered $S$. cerevisiae as a biological inhibitor to prevent rhinovirus-mediated common cold pathogenesis}

George Liu [1], Emily Lam [1]

[1] University of Ottawa, Ottawa, Ontario, Canada K1N 6N5

Over 150 different rhinovirus serotypes are capable of causing the common cold, making this infection of the upper respiratory tract seem almost inevitable. While symptoms are mild for the majority of the population, the common cold can be quite debilitating for at-risk populations, and at the very least, it poses an immense burden on education and employment hours. While there is some existing infrastructure to prevent and treat rhinovirus infections, these methods are often impractical or unsustainable. Our project will use synthetic biology techniques to genetically engineer a cheaper and more effective alternative by expressing ICAM-1 receptors in Saccharomyces cerevisiae. Antibody flow cytometry will be used to test for ICAM-1 expression, then rhinovirus virulence will be assessed via plaque assay. Finally, the engineered microbe will be tested in a mouse model susceptible to rhinovirus infection to see if it can effectively sequester rhinovirus particles alongside other commensal microbes. It all is successful, our yeast can be applied to air filters and nasal sprays, and the techniques will pave the road for further engineering of biological antiviral methods.

\section{The use of CRISPR-X engineered antibodies for immunotherapy in Parkinson's disease Isabell Pitigoi [1], Courtney Ostromecki [1] [1] Queen's University, Kingston, Ontario, Canada K7L 3N6}

Parkinson's disease (PD) is a neurodegenerative disorder characterized by progressive cell death in the substantia nigra portion of the midbrain, causing severe dopamine imbalance and subsequent loss of refined motor control . Pathogenicity arises from the misfolding of the alpha synuclein (a-syn) protein which then oligomerizes to form Lewy body aggregates in neurons. Previous research has identified A30P mutated oligomers as particularly toxic intermediates but there are insufficient methods for targeting them in isolation of other forms of a-syn. Here, we aim to modify existing immunotherapeutic approaches to PD, by use of CRISPR-X and phage display, to design antibodies that are highly specific to the A30P oligomer. We will use CRISPR-X to produce a diverse library of antibodies by introducing point mutations in the sequences encoding their variable light chains. Then, via insertion into bacteriophages for multiple rounds of phage display selection, we should obtain a polyclonal selection of antibodies that exclusively recognize epitopes on A30P a-syn. We expect that measurements from ELISA assays would indicate that the antibodies generated through this mechanism bind with higher affinity to A30P oligomers than other oligomeric forms of a-syn. Given these results, we could anticipate that immunotherapy using this 
UNDERGRADUATE RESEARCH IN NATURAL AND CLINICAL SCIENCE AND TECHNOLOGY (URNCST) JOURNAL Read more URNCST Journal articles and submit your own today at: https://www.urncst.com

antibody will produce a specific reversal of toxic effects of A30P in neuronal tissue. This would establish a potential for CRISPR-X designed antibodies as an immunotherapeutic treatment option for slowing the progression of PD-related cell death.

Hyaluronic acid release from intraocular lens to diminish dry eye symptoms after cataract surgery Chloe Smith [1], Mignon Le Roux [1]

[1] Queen's University, Kingston, Ontario, Canada K7L 3N6

Cataract surgeries are becoming increasingly popular as the population ages. A common postoperative complication is dry eyes, which causes significant discomfort and may impair visual recovery. Intraocular lenses have been used to deliver drugs after insertion into the aqueous humor. Their modification to release hyaluronic acid (HA) may be beneficial in cataract surgery by augmenting the eye's natural ability to create moisture. This experiment consists of testing the safety and feasibility of the release of HA via an intraocular lens in conditions that mimic the eye post-cataract surgery. Using experimental methods such as (1) spectrometry, (2) HA Enzyme-Linked Immunosorbent Assay and (3) LC-MS/MS, the release quantity, rate and longevity of the HA as well as Rapamycin (a common immunosuppressant used in cataract surgery) will be measured. The following study would be the first step in creating a HA-releasing polymer sprayed intraocular lens that would treat dry eyes post-cataract surgery.

\section{A novel transgenic line of transmission-incapable Aedes aegypti via heritable gene silencing using CRISPR Alyssa Ho [1], Yu Bin Tan [1] \\ [1] University Of Toronto Scarborough, Scarborough, Ontario, Canada MIC 1A4}

Dengue virus (DENV) is a mosquito-borne arbovirus that infects an estimated 50-100 million people annually. The main viral vector involved in the transmission of DENV is the Aedes aegypti. Efforts to reduce the spread of DENV via the development of vaccines or by reducing the transmission efficacy of the viral vector have had limited success. We examined the mode of action of the DENV virus in the mosquito-human transmission cycle and discovered that DENV entered the human bloodstream through salivary secretions of an infected Aedes aegypti. This study aims to target this characteristic by using CRISPR to edit the genes of female Aedes aegypti in order to create a non-functional mouthpiece, specifically by targeting the genes coding for the maxillae and mandibles. In this new transgenic model, the secretion of mosquito saliva into the human host would be prevented, thus inhibiting the transmission of DENV. The efficacy of this transgenic model is tested using a novel experimental set-up that simulates the natural process whereby the mosquito detects and bites the human host.

Investigating the potential of magnetoneurography in prosthetics Mura Abdul-Nabi [1], Hamza Inayat [1]

[1] University Of Toronto Scarborough, Scarborough, Ontario, Canada M1C 1A4

Prosthetics provide amputees or those with motor disabilities the opportunity to regain the confidence and independence they once had. However, despite the significant improvements made in the appearance and functioning of prosthetics, there are still many limitations with regards to user comfort functionality. Here, we highlight the potential of using Superquantum Interference Devices (SQUIDs) to detect the magnetic output of peripheral nerves in the arm in a similar way magnetoencephalography (MEG) is used to detect magnetic output of the brain in order to classify and decode information being sent about movements from the central nervous system to the hands. SQUIDs will be used to record the magnetic output of peripheral nerves from healthy participants while performing grasp or reach movements towards various objects in order to test for the possibility of classifying or decoding the movements encoded by the peripheral nerves. This study may highlight the potential for using magnetic output to enhance prosthetics to have faster responses with greater precision.

Fixing Pitx3 gene mutation with CRISPR CAS9 intervention in zygotic aphakia-prone mice Hussam Sheikh [1], Gowsith Thillaiambalam [1], Hassan Alibhai [1] [1] University Of Toronto Scarborough, Scarborough, Ontario, Canada M1C 1A4

Despite the drawbacks of gene-editing, CRISPR-Cas9 is a versatile tool that relies on single guide RNA (sgRNA) and the Cas9 enzyme for genome editing. A case where CRISPR Cas9 could contribute is in the editing of spontaneous deletion 
UNDERGRADUATE RESEARCH IN NATURAL AND CLINICAL SCIENCE AND TECHNOLOGY (URNCST) JOURNAL Read more URNCST Journal articles and submit your own today at: https://www.urncst.com

mutation on the Pitx3 gene. The mutation of Pitx3 causes aphakia in mice and Parkinson's disease (PD) in humans. The Pitx3 gene codes for the Pitx3 transcription factor involved in many tasks including the differentiation of dopaminergic neurons (DN) in the substantia nigra, expression of tyrosine hydroxylase, dopamine transporter and lens development. The aim of our study is to edit mutated Pitx3 genes using CRISPR Cas9 in embryonic dopaminergic progenitor-neurons in mice and compare them to the wildtypes (WT) that do not undergo CRISPR Cas 9 intervention. To test this, we will use 5 female mice, 2 of which homozygotes for mice aphakia (Ak) and 3 pseudo-pregnant. We will also obtain 2 males homozygous (+/+ Ak) mice with aphakia to mate with the female $(+/+\mathrm{Ak})$ aphakia. Dopamine levels in mice will be evaluated using PET cameras after administering radioactive fallypride that has a high affinity to dopamine receptors. We will conduct CRISPR Cas9 intervention on embryonic stem cells (ESC) of aphakic mice and test the success of the intervention based on presence of optical lens, dopamine levels and restriction sequence expression. This research examines the use of CRISPR Cas9 on embryos with mutated genes found in mice and humans that impair lens development and dopaminergic neuronal differentiation.

\section{Bioremediation of anthropogenic methane: Immobilization of sMMO on $E$. coli curli fibres to create catalytic biofilm} Manuela Modrakova [1], Marco Froelich [2]

[1] University of Guelph, Guelph, Ontario, Canada N1G 2W1

[2] McGill University, Montreal, Quebec, Canada H3A 2T5

The oil and gas industry is a major anthropogenic source of atmospheric methane due to gas leaks and gas disposal through venting and flaring. Bioremediation through methanotrophs is of great interest because these bacteria have methane monooxygenase enzymes capable of oxidising methane into methanol under ambient conditions. Bioremediation has had little success in the industry due to the limited functionality of methane monooxygenase when immobilized. This proposal addresses this limitation by using a catalytic biofilm comprised of an engineered curli fibre matrix. Escherichia coli will be engineered with the use of plasmids to express curli fibres that are attached to a protein called SpyTag, which covalently bonds to its partner protein SpyCatcher. Appending methane monooxygenase to SpyCatcher will immobilize the enzyme in the curli fibre matrix, stabilizing it in harsh industrial conditions. Engineered Escherichia coli can be attached to a polyvinylidene fluoride membrane, creating a catalytic biofilm which can in turn adhere to steel surfaces on industrial pipelines. Methane that is passed through these pipelines will be exposed to the biofilm and will be oxidised to produce methanol, consequently decreasing methane emissions. The efficiency of methane remediation with the Escherichia coli biofilm will be predicted using a modified version of the mathematical model created by Yoon $\mathrm{S}$ et al. Based on our adaptations of the mathematical model, it is reasonable to conclude that the biofilm will be efficient in reducing methane emissions from the oil and gas industry.

Bioremediation: How to decrease greenhouse gas emissions through cows Atiya Sekyi-Otu [1], Alexa Smith [1]

[1] University of Guelph, Guelph, Ontario, Canada N1G 2W1

The concentration of greenhouse gases within the atmosphere is currently on the rise. With the increase of human population comes a growing need for greater food security in order to support our population. The agricultural industry has a carbon footprint comparable to that of other extensive producers: oil production facilities, waste sectors and industrial processors . The ability to decrease or eliminate the methane produced from agriculture would be significant findings in current global studies. Combining knowledge from environmental biology, agricultural science, microbiology and animal biology, solutions can be found for reducing the agricultural carbon footprint. In North America, cattle farming practices account for a majority of our food security. The use of bioremediation methods to decrease methane production is a new area of research. By cultivating a microorganism that can compete with the methanogenic bacteria within the rumen of cows, less methane yield is plausible. This study aims to establish an experimental design developed to modify the current cultural microbiome in cattle. Young Canadian Holstein cattle with developing ruminal microbiomes will be placed into control and treatment groups and studied over the duration of 4 weeks. Addition of the Ruminococcus hydrogenotrophicus will be inserted into the rumen of experimental group cattle. Results will generate findings on the basis of reducing methanogenic activity among the rumen of cattle, and therefore be feasible towards the decreasing of the agricultural carbon footprint among the cattle industry.

Ngo et al. | URNCST Journal (2020): Volume 4, Issue 3

DOI Link: https://doi.org/10.26685/urnest.184 
UNDERGRADUATE RESEARCH IN NATURAL AND CLINICAL SCIENCE AND TECHNOLOGY (URNCST) JOURNAL Read more URNCST Journal articles and submit your own today at: https://www.urncst.com

\author{
MicroRNA-mediated inhibition of amyloid beta protein synthesis in Alzheimer's disease \\ Katelyn Wang [1], Kamron Zaidi [1], Alston Lo [1], Will Jeong [1] \\ [1] University Of Toronto St. George, Toronto, Ontario, Canada M5G
}

Alzheimer's Disease (AD) is a progressive neurodegenerative disorder, currently without a cure. A defining feature of AD is the buildup of amyloid beta $(A \beta)$ plaques formed by the cleavage of amyloid beta precursor protein (APP). Thus, we aim to investigate two microRNA (miRNA), miR-106b and miR-153, for their ability to inhibit APP synthesis. Since miR-106b and miR-153s are also deficient in AD patients, we hypothesize that increasing their concentrations in the brain will reduce plaque development, and thereby ameliorate symptoms of AD. To test this hypothesis, five groups of mice will be reared: a control group of healthy C57BL/6J mice, a control group of diseased B6.Cg-Tg(Thy1-APP)3Somm/J mice, a control group of 6.Cg-Tg(Thy1-APP)3Somm/J mice treated with functionless miRNA, and two treatment groups of B6.Cg-Tg(Thy1APP)3Somm/J mice treated with miR-106b and miR-153 each. Then, a Morris water maze test and ELISA analysis will be conducted on each group to determine the effectiveness of the miRNA treatment at reducing A $\beta$ plaque and AD symptoms.

\title{
Combatting the challenges of curcumin bioavailability via transgenic Piper nigrum Samantha Yao [1], Aaron Dou [1], Haymond Yang [1], Alex Xiang [1] \\ [1] University Of Toronto St. George, Toronto, Ontario, Canada M5G
}

Curcumin, a polyphenol found in turmeric (Curcuma longa), has been shown to have many health-promoting effects, including potent antitumorigenic and anti-inflammatory activity. However, curcumin displays poor pharmacokinetics and has very limited bioavailability, restricting its applicability in humans. We propose the transgenic expression of three curcumin biosynthetic genes in the black pepper plant (Piper nigrum) as a potential solution, given that piperine, a compound present in black pepper, has been found to greatly increase curcumin's bioavailability. Treatment of Trp53 knockout mice with a diet rich in the transgenic plant and subsequent comparison to a control will allow for evaluation of the success of this approach. Through combination with piperine in a single, accessible, and edible source, we present an innovative new method to combat the challenges of curcumin bioavailability, and hope to provide a potent health-promoting crop to cancer patients and health individuals alike.

Investigating the effects of five different SNPs on distinct strains of mice to examine the effects of epistasis, and the potential emergence of differential phenotypes Zenan Tang [1], Adel Halawa [1], Nathaniel Linga [1], Anthony Ngoy [1] [1] University Of Toronto St. George, Toronto, Ontario, Canada M5G

The potential to cure monogenic disease with CRISPR/Cas9 is potentially revolutionary, but editing the human genome without careful consideration of all possibilities can be dangerous. Many fear the creation of "designer babies", which could have major evolutionary and socioeconomic consequences. The term implies the ability to tweak the genetic makeup of any individual in order to achieve the desired phenotype. While this might be partly true in simple traits, complicated behavioral traits are generally polygenic, with no one gene isoform having an effect size greater than $1 \%$. One of the most heritable polygenic traits is intelligence, which has many gene isoforms associated with it. These isoforms exhibit pleiotropy and epistasis, and interact with the environment such that phenotype is highly variable. This study aims to show that the editing of genes associated with intelligence using current CRISPR technology is not possible without unwanted consequences. The purpose of this is to both educate the public, and warn overzealous scientists who aim to prematurely use CRISPR on humans again. This will be achieved by simultaneously editing 5 SNPs associated with intelligence in a mouse embryo. All edits will be done on five different strains of mice, and phenotypes would be compared in order to quantify epistatic effects. Multiple behavioural tests will be conducted in order to test memory, associative learning, anhedonia, anxiety, and social behavior. It is hypothesized that the strains will respond differently to the introduction of these SNPs, and that they might cause predisposition towards mood and social disorders. 
UNDERGRADUATE RESEARCH IN NATURAL AND CLINICAL SCIENCE AND TECHNOLOGY (URNCST) JOURNAL Read more URNCST Journal articles and submit your own today at: https://www.urncst.com

Engineering of a novel anti-dioxin Bacillus subtilis probiotic for poultry feed Alyssa Huang [1], Osanda Lee [1], Keyi Guo [1]

[1] University of Waterloo, Waterloo, Ontario, Canada N2L 3G1

Plastic waste incineration has increased dramatically in Asia, producing highly toxic byproducts such as dioxins. The biomagnification and bioaccumulation of dioxins from the atmosphere to the soil, agriculture, feed, livestock, and finally to humans poses a serious concern for public and environmental health. This study aims to engineer a novel poultry feed additive for detoxification of this compound. A method for the creation of a Bacillus subtilis feed probiotic via insertion of a dioxin degradation system from Sphingomonas wittichii and thymine dependant biological containment system will be described in this proposal.

\section{Conflicts of Interest}

The authors have no conflict of interest to declare.

\section{Authors' Contributions}

$\mathrm{CN}$ : President of the Undergraduate Research Initiative, served on the planning committee for the USCC, drafted the conference abstract booklet, and gave final approval of the version to be published.

LM: Co-President of Scinapse and Co-Chair of the USCC planning committee, assisted authors with their abstract submissions, drafted the conference abstract booklet and gave final approval of the version to be published.

RR: Co-President of Scinapse and Co-Chair of the USCC planning committee, assisted authors with their abstract submissions, drafted the conference abstract booklet and gave final approval of the version to be published.

\section{Acknowledgements}

We want to acknowledge the entire Scinapse Provincial Team for playing an integral role in making this year's USCC a big success. The team that helped make this competition possible includes: Linda Mardiros and Rashida Rajgara as CoPresidents of Scinapse and Co-chairs of the planning committee, Clarissa Ngo as President of URI, Justen Choueiry as VicePresident of Finances of URI, Dilpreet Bajwa as Communications Team Lead, Momina Ejaz as Communications Director, Rebecca Krnel as Provincial Coordinator, Misha Kaniyath and Amanda Vandewint as Graphic Designers, Varis Gupta as Mentorship Lead, Rahna Rasouli as Scientific Advisor, Antony El-Khoury as Operations Team Lead, Phanisri Muduniri as Project and Statistics Coordinator, Isaac Kuk as Sponsorship and Statistics Coordinator, Darius Stamatakos and Justin Thomas as uOttawa Campus Leaders, Jasmine Candeliere as Event Manager and Logistics Coordinator, and Laura Mardiros as Executive Assistant.

The USCC would not have been successful without the contribution and work of the multiple different chapters of the Scinapse USCC situated across other universities in Ontario.

We want to acknowledge all the professors and graduate students that participated as judges for the competition. Your valuable time and feedback to the participants has had a positive impact on their future success.

\section{Funding}

The Scinapse USCC is funded by the Undergraduate Research Initiative and contributions from the University of Ottawa Faculty of Science and the Faculty of Medicine.

\section{Article Information}

Managing Editor: Jeremy Y. Ng

Article Dates: Received Feb 27 20; Published Mar 1020

\section{Citation}

Please cite this article as follows:

Ngo C, Mardiros L, Rajgara R. Scinapse 2019-2020 Undergraduate Science Case Competition: Augmented Biology.

URNCST Journal. 2020 Mar 10: 4(3). https://urncst.com/index.php/urncst/article/view/184

DOI Link: https://doi.org/10.26685/urncst.184 
UNDERGRADUATE RESEARCH IN NATURAL AND CLINICAL SCIENCE AND TECHNOLOGY (URNCST) JOURNAL

Read more URNCST Journal articles and submit your own today at: https://www.urncst.com

\section{Copyright}

(C) Clarissa Ngo, Linda Mardiros, Rashida Rajgara. (2020). Published first in the Undergraduate Research in Natural and Clinical Science and Technology (URNCST) Journal. This is an open access article distributed under the terms of the Creative Commons Attribution License (https://creativecommons.org/licenses/by/4.0/), which permits unrestricted use, distribution, and reproduction in any medium, provided the original work, first published in the Undergraduate Research in Natural and Clinical Science and Technology (URNCST) Journal, is properly cited. The complete bibliographic information, a link to the original publication on http://www.urncst.com, as well as this copyright and license information must be included.

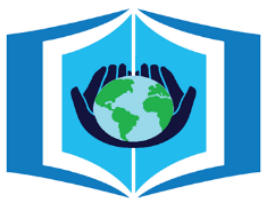

\section{URNCST Journal \\ "Research in Earnest"}

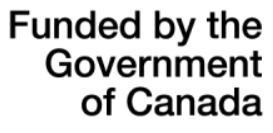

Canadà̀

Do you research in earnest? Submit your next undergraduate research article to the URNCST Journal!

| Open Access | Peer-Reviewed | Rapid Turnaround Time | International |

| Broad and Multidisciplinary | Indexed | Innovative | Social Media Promoted |

Pre-submission inquiries? Send us an email at info@urncst.com | Facebook, Twitter and LinkedIn: @URNCST

Submit YOUR manuscript today at https://www.urncst.com!
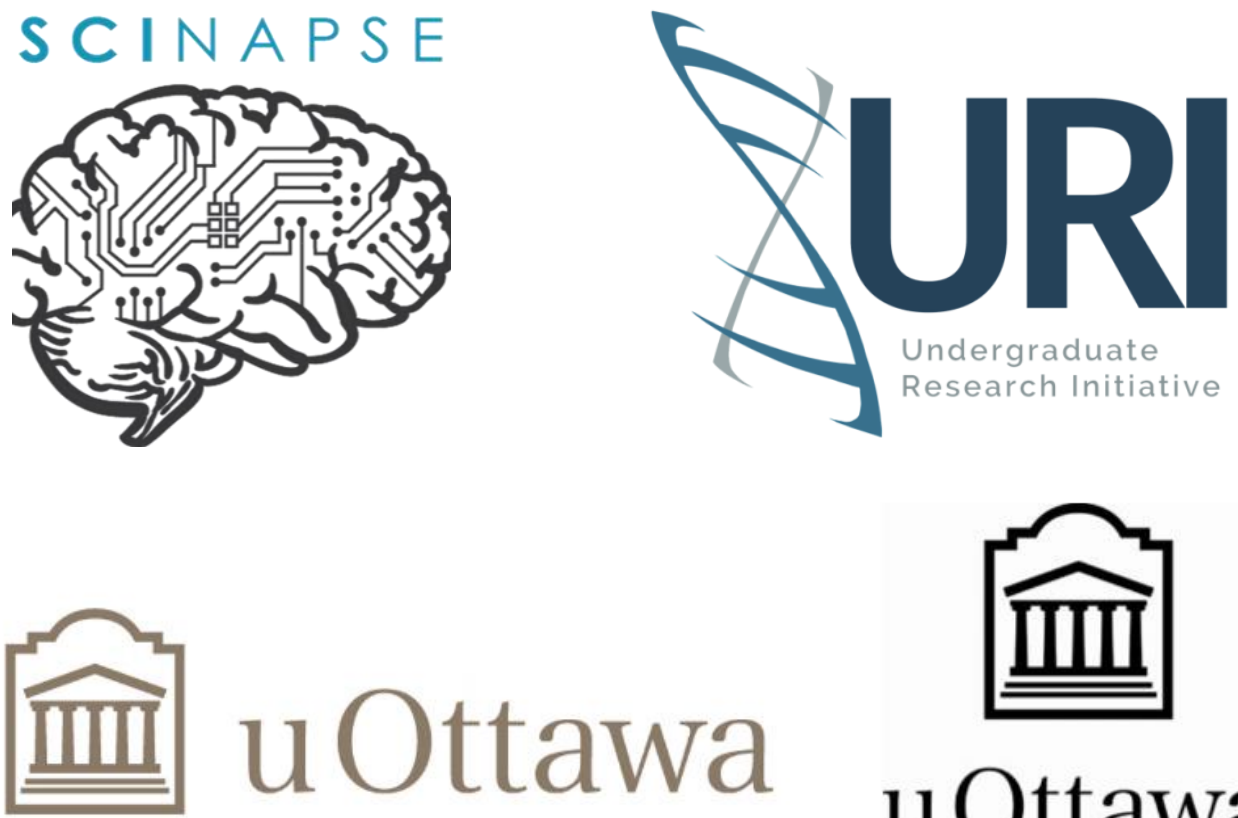

u Ottawa

Faculté de médecine Faculty of Medicine

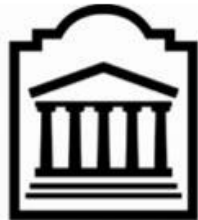

uOttawa

Faculté des sciences

Faculty of Science 